\title{
\begin{tabular}{l|l} 
pcori)? & PATIENT-CENTERED OUTCOMES RESEARCH INSTITUTE \\
RESEARCH SUMMARY
\end{tabular}
}

PROJECT INFORMATION

July 2021

\section{Including Patients in the Governance of Learning Health Systems}

Principal investigator

Steven Joffe, MD, MPH
Organization

University of Pennsylvania

\section{What was the project about?}

A learning health system, or LHS, is a health system that constantly looks for new ways to improve patient care. At an LHS, doctors and other hospital staff use learning activities to improve care, put what they've learned into practice, and share findings with other hospitals. Activities may include doing studies that compare treatments to see which one works better for which patients.

Governance refers to the way LHSs oversee learning activities. Governance includes people, committees, and policies that regulate learning activities. Including patients as partners in governance helps make sure learning activities address what's important to patients and protect patients' rights and interests. But LHSs don't always include patients in governance.

In this study, the research team wanted to learn how LHSs include patient partners in governance. The team interviewed patients and health system leaders to answer this question.

\section{What did the research team do?}

The research team interviewed 99 people from 16 LHSs across the United States by phone. The team talked with patient partners, family members, and LHS senior staff. Of the 16 LHSs, 7 were connected to medical schools that train doctors and 9 weren't.

The research team also held eight focus groups with 77 community members in four cities. Of these, 80 percent were White, 6 percent were Black, 3 percent were Asian, 3 percent were American Indian/Alaska Native, and 3 percent reported another race. In addition, 12 percent were Hispanic, and 51 percent were men.

Then the research team created a summary of the results. They sent a survey to the people they interviewed. The survey asked whether the results were accurate.

A patient partner and an advisory board including patients and family members gave input on the study.

\section{What were the results?}

Patient partners had different levels of involvement in LHSs. In some, patients gave input but didn't take part in research processes or help make decisions. In others, patients were much more involved. In those LHSs, patients took part in all aspects of the research process and helped make decisions. Also, some LHSs had detailed processes for including patient partners in governance.

When patient partners were involved in governance, they gave input on

- Choosing research topics

- Designing studies and collecting data to see how learning activities affect patients

- Putting findings from learning activities into practice

- Sharing findings with other hospitals and health systems 
- Protecting the rights of patients who take part in studies

The research team also learned how LHSs could improve ways to include patient partners in governance, such as

- Creating systems to make sure they can take part

- Training patients who want to be more involved

- Identifying steps for them to become more involved

\section{What were the limits of the project?}

The study included 16 LHSs. Results may differ in other LHSs.

Future research could examine how to involve patient partners consistently across LHSs.

\section{How can people use the results?}

LHSs can use the results when looking for ways to include patients in governance.

To learn more about this project, visit www.pcori.org/Joffe381. 